\title{
Modeling and Stress Analysis of Single Lap Bolted Joint
}

\author{
Jagdev S. Pawar ${ }^{1, *}$, M.Chouksey ${ }^{2}$, K. Tripathi ${ }^{2}$ \\ ${ }^{1}$ Shri Govindram Seksaria Institute of Technology and Science, Indore, India \\ ${ }^{2}$ Department of Mechanical Engineering, Shri Govindram Seksaria Institute of Technology and Science, Indore, India
}

Copyright (C) 2015 Horizon Research Publishing All rights reserved.

\begin{abstract}
Computer aided models are used to present physical systems. These models further find their use in various type of analysis including static and dynamic analysis. In this work computer aided modeling of components of bolted joint and their finite element analysis has been carried out through ANSYS workbench software under definite loading conditions, to obtain different stress and displacement values. The models of the plates, bolt, nut have been made in a CAD software. The model thus made has been imported in the Ansys Workbench for the analysis using the IGES file format. The analysis includes detailed stress analysis of a single lap bolted joint. The spatial variation of total deformation, directional deformation, equivalent stresses and principal stresses is shown. The effect of preload has also been investigated on all these quantities. It has been shown that with increasing pretension the deformation and stresses increase.
\end{abstract}

Keywords Bolted Joint, Stress Analysis

\section{Introduction}

Most of machines and products have various joints such as bolted joint, riveted joint, welded joint etc for effective productivity and maintainability. Bolted joint, one of the joint structures is widely used due to its easiness to install and remove. These joints produce big fastening power with less force and low cost in the production. Bolted joints are one of the most common elements in construction and machine design. They consist of fasteners that capture and join other parts, and are secured with the mating of screw threads.

\section{Literature Review}

Bolted joints are probably the best choice to apply a desired clamp load to assemble a joint, with the option to disassemble if and when necessary [1]. The threaded fastener (nut and bolt) has played a significant role in the industrial revolution even though the exact date of its conception is not known. The concept of a helical thread was first introduced by Archimedes in the 3rd century B.C. Some archeologists argue that the threaded fastener was in existence even before Archimedes at the "Hanging Gardens of Babylon". It is accepted that the common forms of threaded fastener assemblies have been in existence for at least 500 years [3]. History of evolution of screw fasteners dates back to few thousand years ago. It is learnt that screw fasteners were used in the Tigris-Euphrates region in around 1,000 B.C., mainly, for the purpose of water supply. The plate shaped cross-section of the screw thread was then used. The People of Greece were also supposed to use screws to press olives. Leonardo da Vinci is credited for creating and sketching different ideas leading to implementation of important usage of screw threads [1].

This work includes the numerical studies in static analysis of single lap bolted joint. The model has been developed in the CAD software. Stress analysis has been carried out using finite element method. Static analysis is a multi-discipline Computer Aided Engineering (CAE) tool that analyzes the physical behavior of a model to better understand and improve the mechanical performance of a design[2]. It can be used to directly calculate stresses, deflections and thus to predict the behavior of the design in the real world. for analyzing the problem, various elements were modeled using Pro-Engineer 4.0. These solid models are imported in ANSYS workbench for meshing, and the meshed model was subjected to boundary condition as loads and constraints. Then a deck is generated for solver and template is solved using ANSYS workbench.

\section{Numerical Example}

This section demonstrates the stress analysis of single lap bolted joint using finite element method. The dimensions of the single lap bolted joint considered in this work are taken after following " Research council of structural connections," Specification for Structural Joints Using High-Strength Bolts," December 31, (2009) [4].

\subsection{Details of Dimensions of the Bolted Joint}


Table 1. Details of dimension of components of single lap bolted joint

\begin{tabular}{|c|c|}
\hline Width of plate $(\mathrm{w})$ & $66 \mathrm{~mm}$ \\
\hline Thickness of plate 1 (t) & $20 \mathrm{~mm}$ \\
\hline Thickness of plate 2 (t) & $30 \mathrm{~mm}$ \\
\hline Length of plate (L) & $340 \mathrm{~mm}$ \\
\hline Diameter of hole(D) & $16 \mathrm{~mm}$ \\
\hline Distance from hole in plate 1 & $80 \mathrm{~mm}$ \\
\hline Distance from hole in plate 2 & $80 \mathrm{~mm}$ \\
\hline
\end{tabular}

Table 2. Dimensions of bolt and nut

\begin{tabular}{|c|c|}
\hline Nominal length, $\mathrm{L}$ & $340 \mathrm{~mm}$ \\
\hline Nominal diameter, D & $16 \mathrm{~mm}$ \\
\hline Height of bolt, $\mathrm{H}$ & $70 \mathrm{~mm}$ \\
\hline Height of nut & $10 \mathrm{~mm}$ \\
\hline Width across corners, C & $20 \mathrm{~mm}$ \\
\hline
\end{tabular}

In this section, details of various components of single lap bolted joint are described. Table 1 shows the dimensions of plate 1 , plate 2 along with details of hole in it.

The dimensions of nut and bolt considered are shown in Table 2

\subsubsection{Drafting of Components of single lap bolted joint}

Dimensions of the plate 1 and plate 2 are shown in Figure 1 and Figure 2respectively. The location of hole for accommodating the bolt is also shown in the figures.

\subsection{Drafting and Dimensioning of Bolt and Nut}

The dimensions of the bolt and nut considered in the work are shown in Figure 3 and Figure $\mathbf{4}$ respectively.

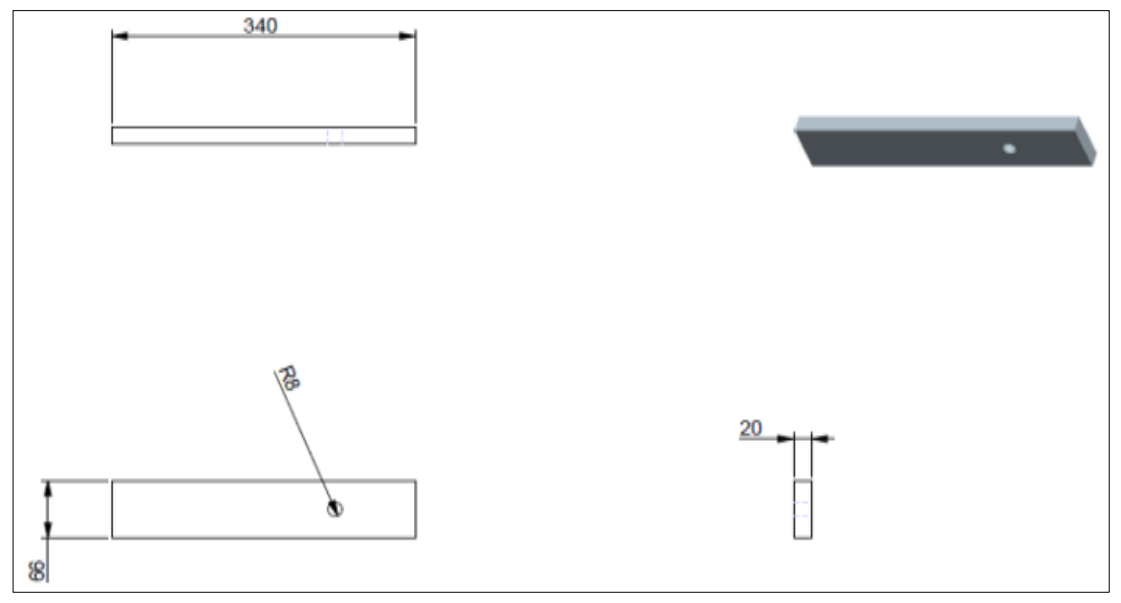

Figure 1. drafting and dimensioning of plate 1

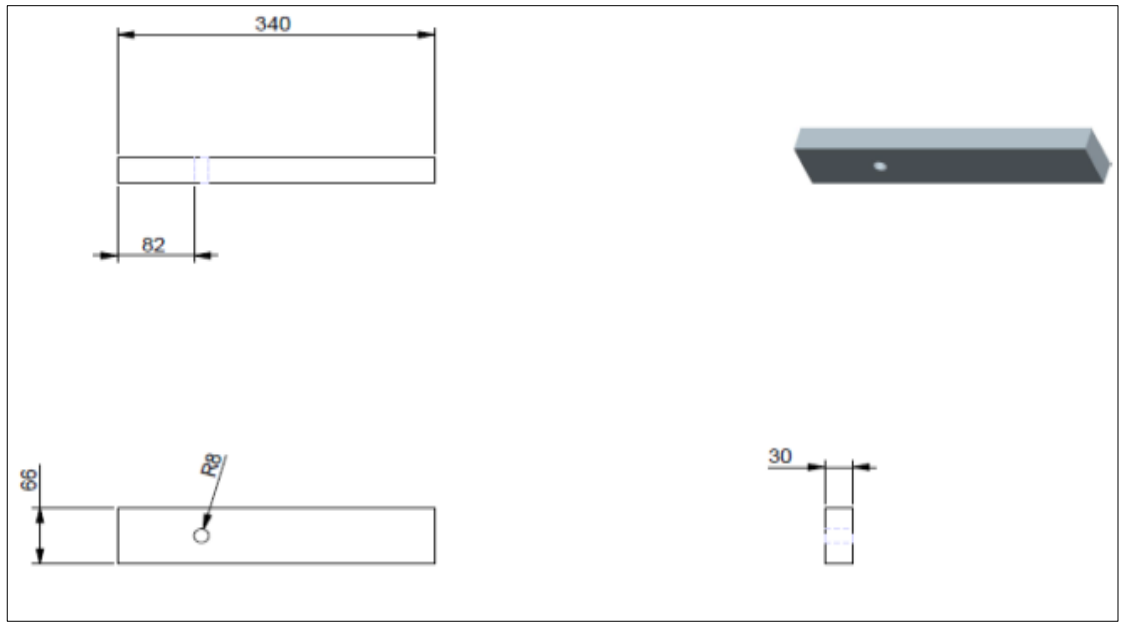

Figure 2. drafting and dimensioning of plate 2 


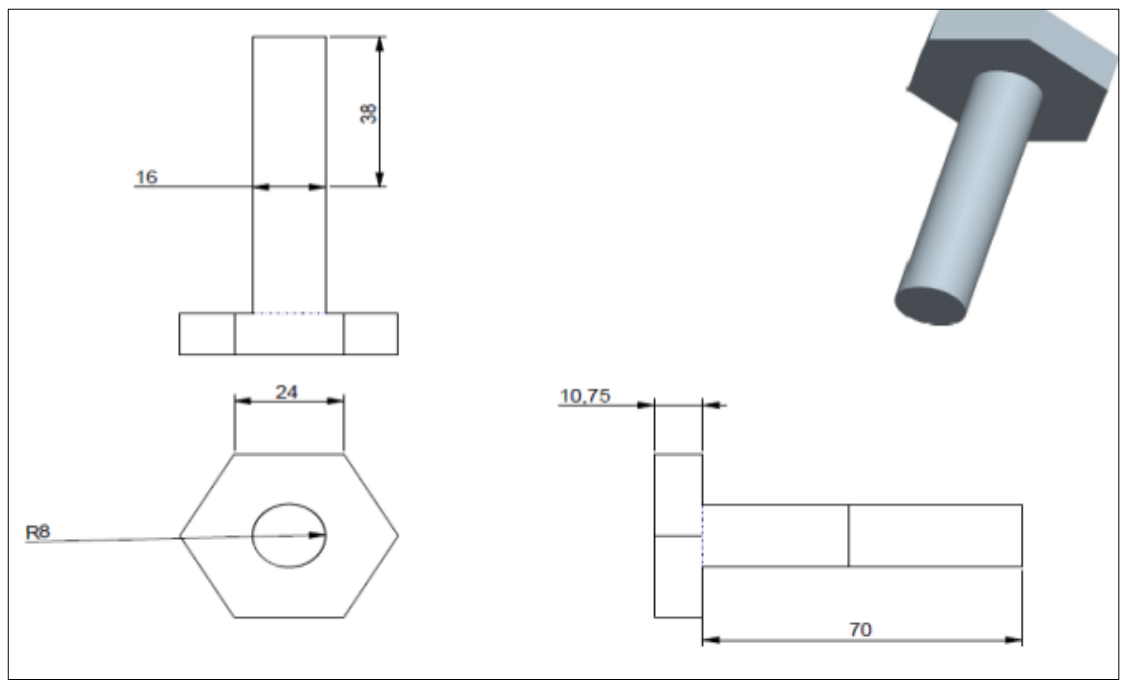

Figure 3. drafting and dimensioning of bolt

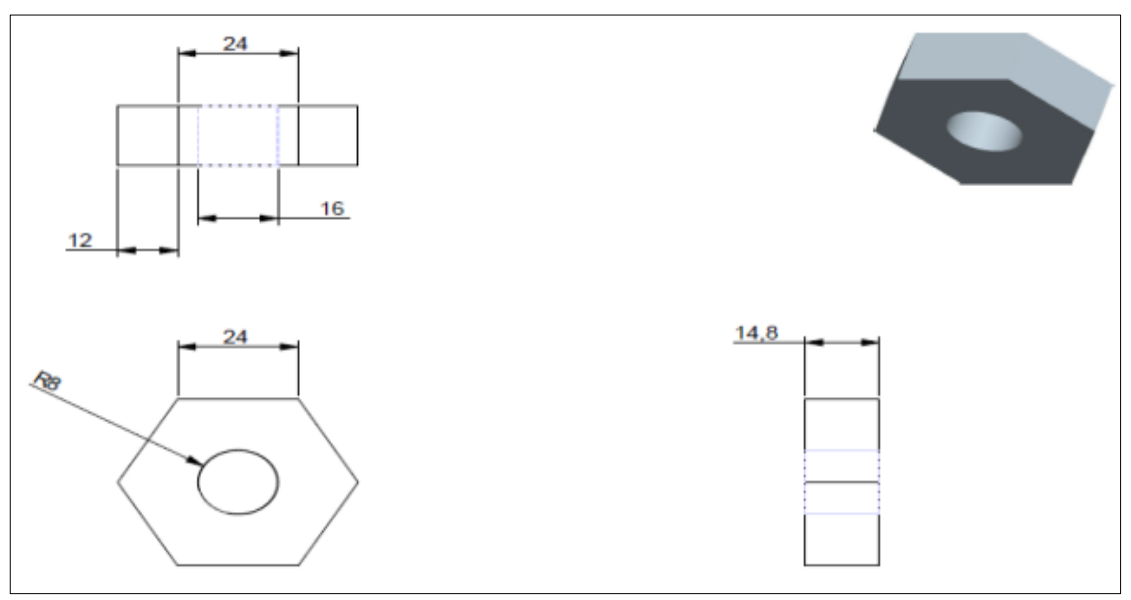

Figure 4. drafting and dimensioning of nut
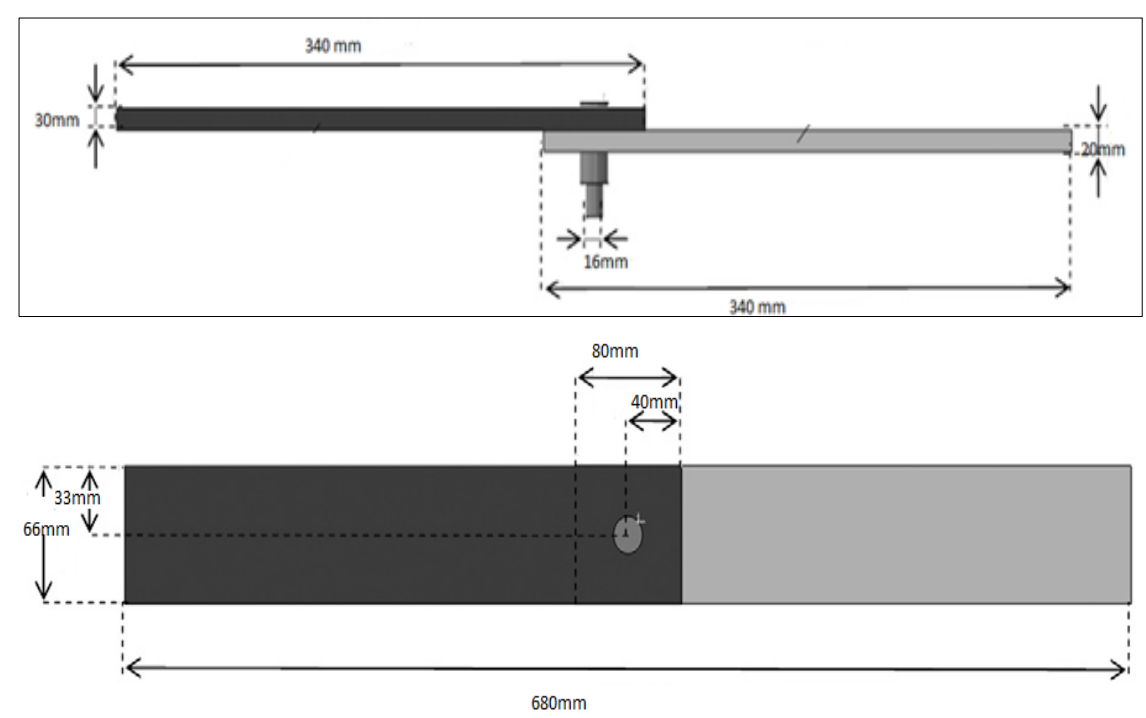

Figure 5. Drafting and dimensioning of final assembly

\subsection{Drafting and Dimensioning of Final Assembly}

Assembly drawing of the single lap bolted joint is shown in Figure 5.

Modeling of the bolted joint
In this paper, the Pro-Engineer software has been used for modeling purpose of the bolted joint.

Figure 6(a) and (b) show the solid model of the plate 1 and plate 2 respectively. Figure 7 shows the solid model of bolt along with nut. 


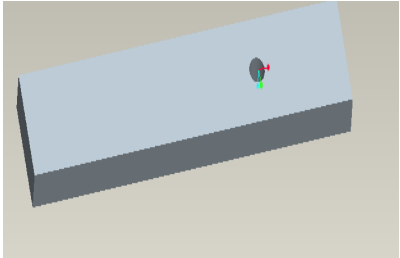

(a)

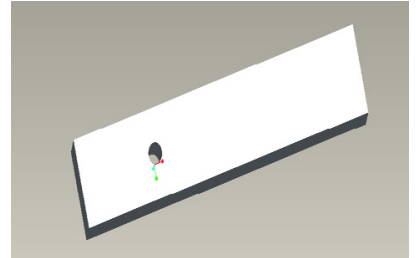

(b)
Figure 6. Solid models(a) Plate 1 (b) Plate 2

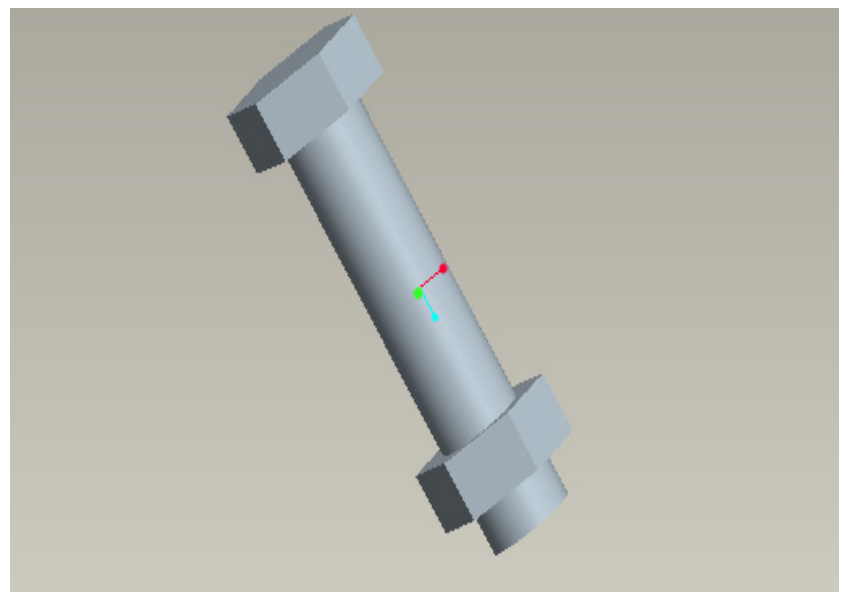

Figure 7. Solid model of M16 Bolt

All the components such developed are assembled and the assembled model of single lap bolted joint assembly as shown in Figure 8.

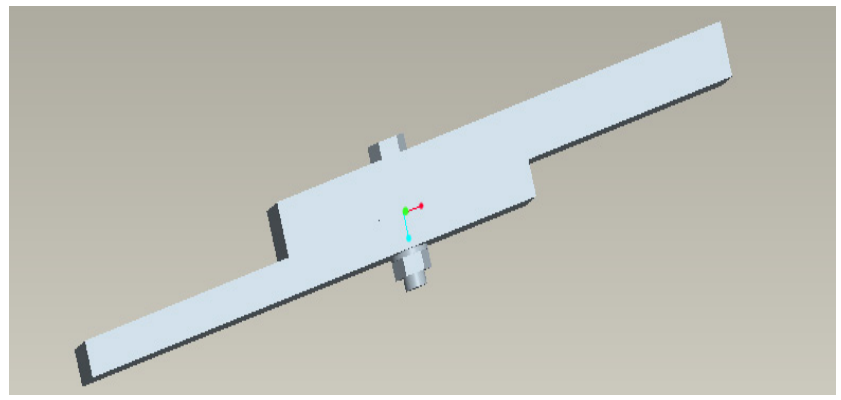

Figure 8. Schematic model of final Assembly

Material Properties nut and bolt

Material properties such as modulus of elasticity, Poisson's ratio are shown in Table 3.

Table 3. Material Properties and dimension of nut and bolt

\begin{tabular}{|c|c|}
\hline Material type & Medium carbon steel \\
\hline Modulus of elasticity, E & $200 \mathrm{Gpa}$ \\
\hline Poisson's ratio, $\AA$ & 0.30 \\
\hline Proof strength & $580 \mathrm{Mpa}$ \\
\hline Minimum tensile yield strength & $640 \mathrm{Mpa}$ \\
\hline
\end{tabular}

Material Properties of plates

Table 4. Material Properties and dimension of plates

\begin{tabular}{|c|c|}
\hline Material type & Mild steel \\
\hline Modulus of elasticity & $200 \mathrm{Gpa}$ \\
\hline Poisson's ratio & 0.30 \\
\hline
\end{tabular}

\section{Finite Element Analysis of Bolted Joint}

The assembly for the bolted joint has been imported in ANSYS workbench for meshing, and the meshed model was subjected to boundary condition, loads and constraints. Then a deck is generated for solver and template is solved using workbench [5].

\subsection{Pre-processing in ANSYS Workbench}

Firstly, IGES file format of bolted joint Assembly has been imported in ANSYS workbench for static analysis.

\subsection{Geometry Selection and Mesh Genration for Static Anaysis as Shown in Fig.}

Figure 9 shows the assembly of the single lap bolted joint as obtained after importing it from Pro-Engineer software in IGES format. This assembly is further used for meshing the structure, and the meshed bolted joint is shown in Figure 10.

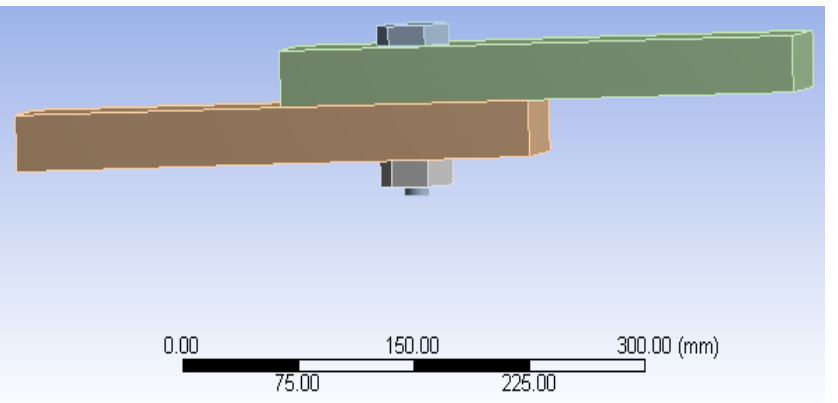

Figure 9. Assembled model in ANSYS workbench

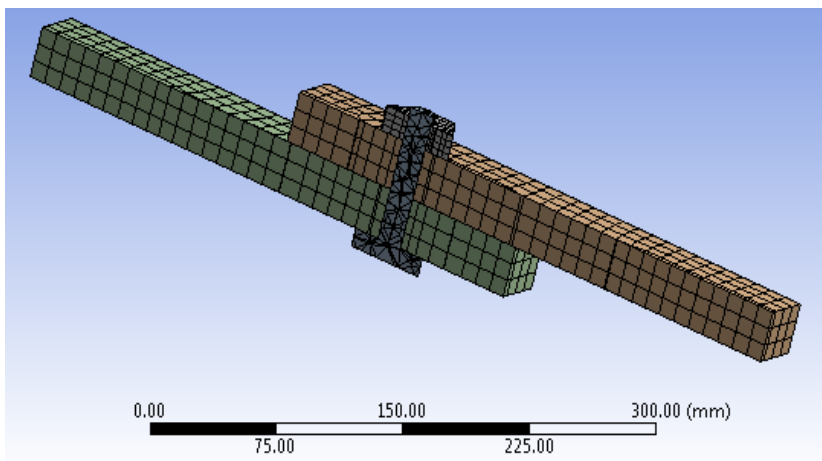

Figure 10. meshing of bolted joint assembly

\subsection{Applying Boundary Condition to the Bolted Joint Assembly}

Figure 11 and Figure 12 show the application of load and boundary condition for the analysis of the single lap bolted joint. A force of $5000 \mathrm{~N}$ has been applied at one surface.

Selecting one surface as fixed surface as shown in figure 12

Application of pretension load is shown in Figure 13, which shows applying bolt pretension $(5000 \mathrm{~N})$ on the model. 


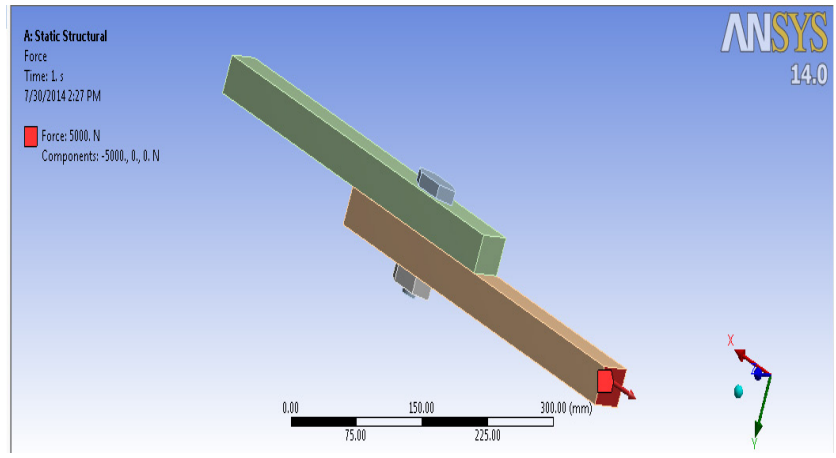

Figure 11. Applying boundary condtion to the model

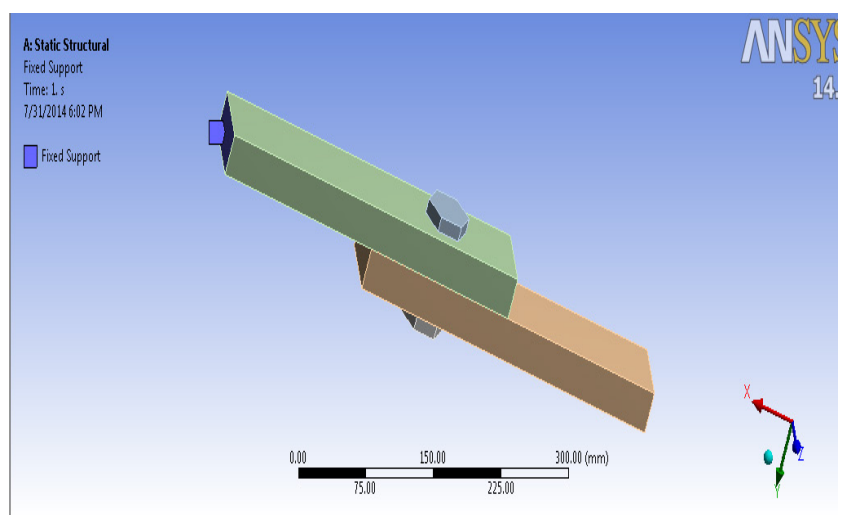

Figure12 . fixed surface on one plate

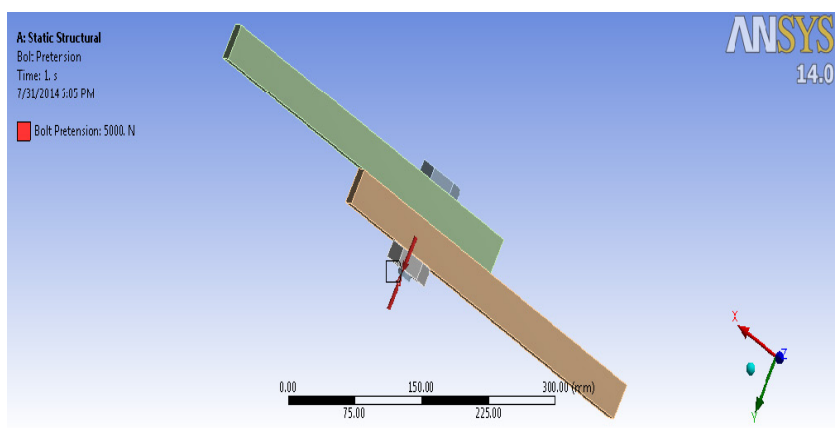

Figure 13. bolt pretension

\subsection{Solution in ANSYS Workbench}

After applying the boundary condition and applying the external and pretension load, the model has been solved for stress analysis. Maximum total deformation in $\mathrm{mm}$ is found to be 0.4124 as shown in Figure 14 (a).

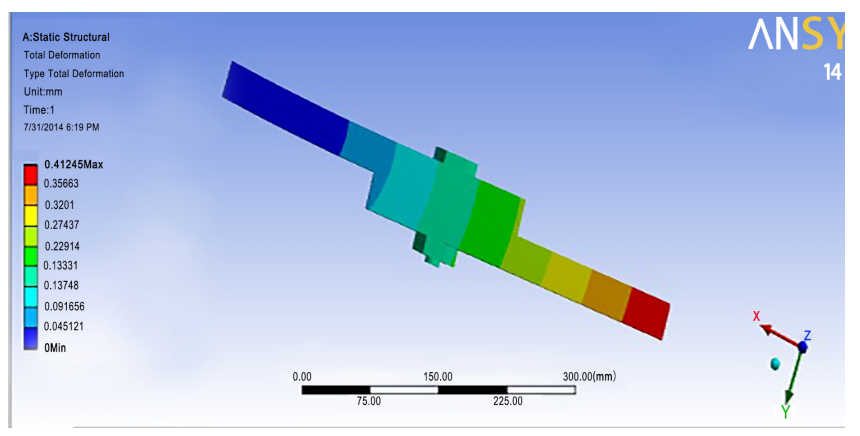

(a)

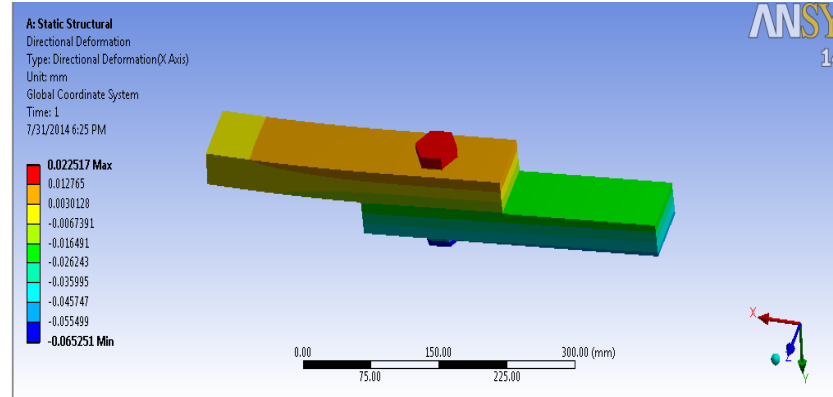

(b)

Figure 14. (a) total deformation (b)

Maximum directional deformations in $\mathrm{mm}$ is (.0225) as shown in Figure 14(b).Maximum equivalent (Vonmises ) stress in MPa is 27.25 as shown in figure Figure $\mathbf{1 5 .}$

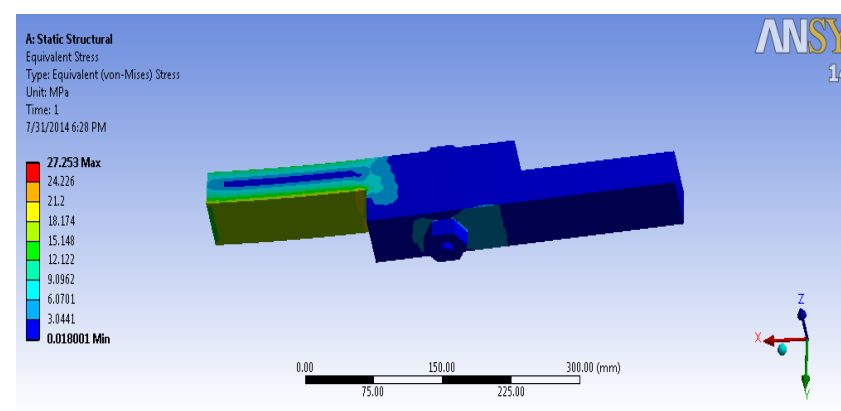

Figure 15. Equivalent stress

Whereas maximum principal stress in MPa is found to be 35.187 as shown in Figure 16.

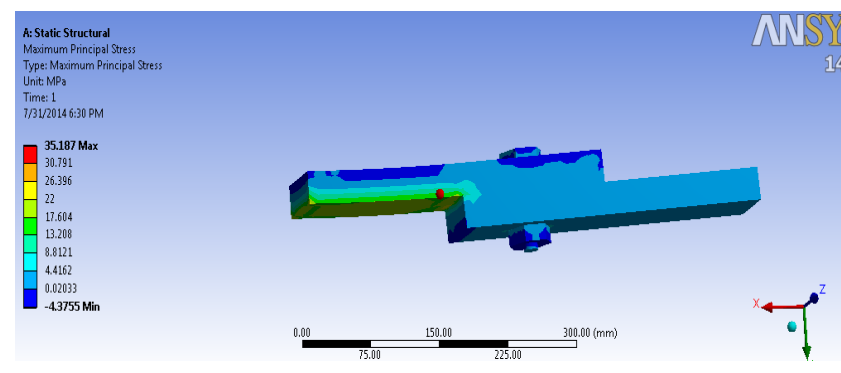

Figure 16. maximum principal stress

\section{Displacement and Stress Analysis Results}

In this section the results of static analysis are presented when the pretension ranges from $500 \mathrm{~N}$ to $5000 \mathrm{~N}$. Maximum and minimum value of results is shown in Table 5 and Table 6 respectively. These include the results of total deformation, directional deformation, equivalent stress and maximum principal stress. The table shows that as the pretension load increases the total deformation, directional deformation, equivalent stress and maximum principal stresses increase. Similar variation has been shown with the help of plots as shown in Figure 17 and Figure 18. 
Table 5. maximum values of all result data

\begin{tabular}{|c|c|c|c|c|c|}
\hline Pretension Load & $1000 \mathrm{~N}$ & $2000 \mathrm{~N}$ & $3000 \mathrm{~N}$ & $4000 \mathrm{~N}$ & $5000 \mathrm{~N}$ \\
\hline Total Deformation(mm) & 0.1935 & 0.2875 & 0.3231 & 0.3912 & 0.4124 \\
\hline Directional Deformation(mm) & 0.00433 & 0.00937 & 0.01263 & 0.01853 & 0.02251 \\
\hline Equivalent Stress(MPa) & 11.634 & 14.975 & 18.637 & 21.436 & 27.253 \\
\hline Maximum Principal Stress(MPa) & 14.583 & 20.687 & 28.145 & 31.925 & 35.187 \\
\hline
\end{tabular}

Table 6. minimum values of stresses

\begin{tabular}{|c|c|c|c|c|c|}
\hline \multicolumn{7}{|c|}{ MINIMUM VALUES } \\
\hline Pretension Load & $1000 \mathrm{~N}$ & $2000 \mathrm{~N}$ & $3000 \mathrm{~N}$ & $4000 \mathrm{~N}$ & $5000 \mathrm{~N}$ \\
\hline Total Deformation(mm) & 0.0097 & 0.0186 & 0.0316 & 0.0386 & 0.0458 \\
\hline Directional Deformation(mm) & 0.001045 & 0.001746 & 0.002164 & 0.00274 & 0.00312 \\
\hline Equivalent Stress(MPa) & 1.668 & 1.843 & 2.368 & 2.813 & 3.044 \\
\hline Maximum Principal Stress(MPa) & 0.0096 & 0.0116 & 0.0143 & 0.0186 & 0.0203 \\
\hline
\end{tabular}

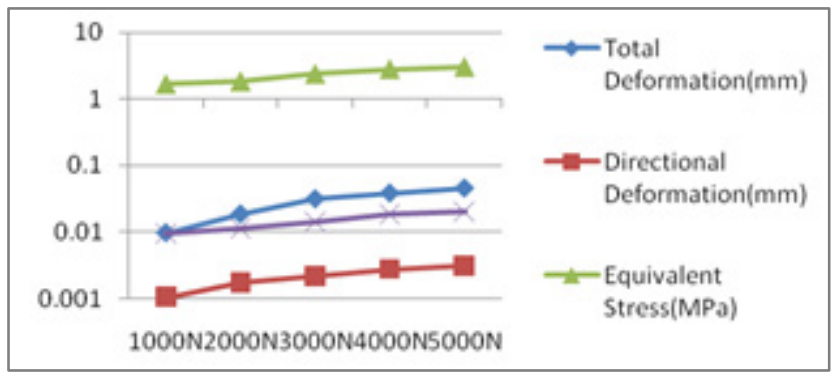

Figure 17. Variation of maximum deformation and maximum stresses as the pretension load increases

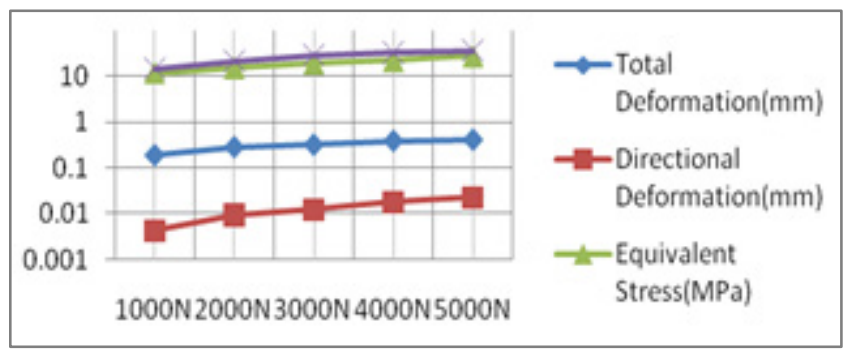

Figure 18. Variation of minimum deformation and minimum stresses as the pretension load increases

\subsection{Conclusions}

The work included the detailed stress analysis of a single lap bolted joint. Solid models of the components of the bolted joint were created in a CAD software and the assembled model was then used for the analysis in ANSYS workbench software. The spatial variation of total deformation, directional deformation, equivalent stresses and principal stresses has been discussed. The effect of preload has also been investigated on all these quantities. It has been shown that with increasing pretension the deformation and stresses increase.

\section{REFERENCES}

[1] Restivo G., Marannano G., and Isaicu G., (2010), “Three dimensional strain analysis of single lap bolted joints in thick composite using fibre optics gauges and the finite element method", Strain Analysis, Vol. 45, pp. 523-534.

[2] Kadam S.S., and Joshi S.G., (2010),"Vibration induced bolt loosening analysis using taguchi and reliability approach", $3^{\text {rd }}$ International Conference on Mechanical.

[3] Zhang, R., and Jianmin, J.U., (2008), "Finite Element Analysis Based on Pro-Engineer,Hyper Mesh and ANSYS",IEEE, International Conference on Computer Science and Software Engineering, Vol 431, pp.622-625.

[4] Mahato K.N., and Das S., (2009), “A study on anti loosening characteristics of different $3 / 8$ BSW threaded fasteners", $14^{\text {th }}$ National Conference on Machines and Mechanism, NIT, Durgapur, India.

[5] ANSYS workbench version 14.0, ANSYS inc, 2012 